\title{
Effect of Different Dosage Frequency of Polymyxin $B$ on Rat Nephrotoxicity
}

This article was published in the following Dove Press journal:

Drug Design, Development and Therapy

\author{
Wenrui Sun ${ }^{1, *}$ \\ Binchuan $\mathrm{Hu}^{2}, *$ \\ Xiaoshan Zhang ${ }^{1,3}$ \\ Yuzhen Wang ${ }^{1,3}$ \\ Zheng Xiang ${ }^{3}$ \\ Guanyang Lin'
}

'The First Affiliated Hospital of Wenzhou Medical University, Wenzhou, 325000, People's Republic of China; ${ }^{2}$ Yongjia People's Hospital, Wenzhou, 325I00, People's Republic of China; ${ }^{3}$ Wenzhou Medical University, Wenzhou, 325000, People's Republic of China

*These authors contributed equally to this work
Correspondence: Guanyang Lin The First Affiliated Hospital of Wenzhou Medical University, Nanbaixiang Street, Wenzhou, 325000, People's Republic of China

Tel/Fax +86 1055579706

Email13867702133@I63.com
Background: Polymyxin B, as the final treatment against multidrug-resistant Gramnegative bacilli, is widely used in clinical practice. However, little is known about the nephrotoxicity of polymyxin $\mathrm{B}$. The purpose of this study was to elucidate the relationship between polymyxin B nephrotoxicity and daily administration frequency.

Methods: Sprague-Dawley rats were randomly divided into three groups: $18 \mathrm{mg} / \mathrm{kg} / \mathrm{q} 24$ $\mathrm{h}$ group (Group A, once daily), $9 \mathrm{mg} / \mathrm{kg} / \mathrm{q} 12 \mathrm{~h}$ group (Group B, twice daily), and normal saline control group (Group C). The rats were injected subcutaneously for 5 consecutive days with the same daily total dose and different frequency of administration. The serum creatinine (SCr) and blood urea nitrogen (BUN) of each group before administration $(0 \mathrm{~h})$, and 8 and $24 \mathrm{~h}$ after administration, were measured by tail vein blood sampling. On the sixth day, the rats in each group were killed, the left kidney was taken for pathological section observation, and the results of each group were compared.

Results: After $96 \mathrm{~h}$ of administrated polymyxin B, the total average level of $\mathrm{SCr}$ in Group A was $56.98 \pm 12.42 \mu \mathrm{mol} / \mathrm{L}$, that of Group B was $52.02 \pm 8.68 \mu \mathrm{mol} / \mathrm{L}$, and that of Group $\mathrm{C}$ was $34.36 \pm 5.39 \mu \mathrm{mol} / \mathrm{L}$. BUN was $9.86 \pm 4.58,10.54 \pm 4.08$, and $3.55 \pm 0.73 \mathrm{mmol} / \mathrm{L}$ in Groups A, B, and C, respectively. The daily urinary protein excretion was $5004.45 \pm 1333.84$ $\mu \mathrm{g}$ in Group A, 4608.04 $\pm 1444.42 \mu \mathrm{g}$ in Group B, and 2096.33 $\pm 215.28 \mu \mathrm{g}$ in Group C. In addition, according to the observation of pathological slices, compared with Group A, the number of exfoliated and necrotic cells of renal tubules in Group B was higher, and the morphological changes were more serious.

Conclusion: The experimental results showed that the renal toxicity in rats treated with a twice-daily subcutaneous dose of polymyxin B was higher than that in rats treated with once-daily dose of polymyxin B.

Keywords: polymyxin B, dose, frequency, renal, nephrotoxicity

\section{Introduction}

In recent years, as a result of the unreasonable use of antibacterial drugs, bacterial multidrug resistance (MDR) has become widespread, so the treatment of severe infection caused by multidrug-resistant bacteria has become a common problem faced by the World Health Organization. ${ }^{1}$ However, owing to the difficulties involved in the research and development of new antibiotics, there are fewer and fewer effective drugs available in clinical practice, and the development of new antibiotics has been significantly slower than the rapid rise of drug-resistant bacteria. As a result, some old antibiotics, which were abandoned and not developed completely, have attracted people's attention again. Among them, the drug polymyxin B is attracting our attention. It was found that polymyxin B was effective as 
a last-resort treatment for infections caused by multidrugresistant Gram-negative bacilli (especially Acinetobacter baumannii, Pseudomonas aeruginosa, and Klebsiella pneumoniae). ${ }^{2}$ According to the International Consensus Guidelines for the Optimal Use of the Polymyxins, the loading dose of polymyxin B for intravenous dosing is $2.0-2.5 \mathrm{mg} / \mathrm{kg}$ (equivalent to $20,000-25,000 \mathrm{IU} / \mathrm{kg}$ ), based on total body weight over $1 \mathrm{~h}$. For patients with severe infections, polymyxin $\mathrm{B}$ can be infused $\mathrm{n}$ a dose adjusted to $1.25-1.5 \mathrm{mg} / \mathrm{kg}$ every $12 \mathrm{~h}$. However, investigations regarding dosing regimens (eg, once a day, multiple times a day, or continuous infusions) or other novel dosing strategies and their impact on nephrotoxicity should also be undertaken. ${ }^{3}$ In addition, the renal toxicity of the drug is high, and the prophase pharmacological research is insufficient, which limits the best clinical therapeutic use of the drug.

Regarding the nephrotoxicity of polymyxin B, it has been determined that polymyxin B can selectively accumulate in renal proximal convoluted tubule epithelial cells, causing epithelial cell necrosis, thereby triggering acute tubular injury. ${ }^{4,5}$ In addition, it was found in experiments that polymyxin B can cause a decrease in renal blood flow and an increase in vascular resistance in rats, which may also be related to nephrotoxicity. ${ }^{6}$ However, in general, the specific cause of nephrotoxicity caused by polymyxin B is still not fully understood. Abdelraouf et $\mathrm{al}^{7}{ }^{7}$ through experiments on rats, found that at the same total daily dose, a dose of $5 \mathrm{mg} / \mathrm{kg} / \mathrm{q} 6 \mathrm{~h}$ produced nephrotoxicity more rapidly than a dose of $20 \mathrm{mg} / \mathrm{kg} / \mathrm{q} 24 \mathrm{~h}$, and that the concentration of polymyxin B in the kidney tissues of the $5 \mathrm{mg} / \mathrm{kg} / \mathrm{q} 6 \mathrm{~h}$ group was higher, indicating that the effect of polymyxin $\mathrm{B}$ on rat renal toxicity is related not only to the dose, but also to the frequency of daily administration. Thus, dividing the dose with more frequent administration may cause greater nephrotoxicity. However, Okoduwa et $\mathrm{al}^{8}$ expressed inconsistent views on this. Through a clinical retrospective study, they found that compared with two separate doses per day, patients with once-daily administration had a higher incidence rate of nephrotoxicity, and there was no difference in the time of occurrence of acute kidney injury between the two groups. Therefore, we urgently need to carry out studies to assess the effect of frequency of administration of polymyxin B on nephrotoxicity to further explain the pharmacological characteristics of the drug, which will provide references for the design of clinically safe and rational medication regimens.

\section{Materials and Methods}

\section{Antimicrobial Agents}

For the animal studies, sulfated polymyxin $\mathrm{B}$ injection (1 $\mathrm{mg}$ polymyxin $\mathrm{B}$ freeze-dried powder equivalent to $6300 \mathrm{U})$ was produced by Shanghai First Biochemical Pharmaceutical Co. (batch number: 20170908). Before the experiment, $0.9 \%$ sodium chloride injection solution was used to prepare $1 \mathrm{mg} / \mathrm{mL}$ polymyxin B solution, which was used in the experiments.

\section{Animals}

Male Sprague-Dawley (SD) rats (weight 220-250 g, 8-12 weeks old; purchased from Slake Experimental Animal Co., Shanghai, China) were used. The rats received food and water ad libitum. The rats were given at least $24 \mathrm{~h}$ to acclimatize before the start of the experiments. All animals were cared for in accordance with the highest humane and ethical standards, as approved by the Institutional Animal Care and Use Committee of the Wenzhou Medical University (permission number: wydw2018-0002), in accordance with the National Institutes of Health (NIH) Guidelines for the Welfare and Use of Animals.

\section{Animal Experimental Methods}

Fifteen healthy male SD rats were divided into three groups, with five rats in each group. Group A: once a day, $18 \mathrm{mg} / \mathrm{kg}$ of polymyxin B was given subcutaneously for 5 consecutive days; Group B: twice a day, $9 \mathrm{mg} / \mathrm{kg}$ of polymyxin $\mathrm{B}$ was given subcutaneously for 5 consecutive days; Group C: the same amount of physiological saline was given subcutaneously every day.

\section{Sample Collection and Preparation}

Urine: SD rats in each group were placed in a metabolic cage (one for each rat) 1 day before the experiment. The rats could drink water freely. The urine of each rat was collected every day, the volume was recorded, and $1 \mathrm{~mL}$ was stored in $\mathrm{a}-20^{\circ} \mathrm{C}$ refrigerator for later measurement.

Plasma: before administration $(0 \mathrm{~h})$, and at $8,24,32$, $48,56,72,80$, and $96 \mathrm{~h}$ after administration, blood was collected from the tail vein of SD rats in each group once (about $0.3 \mathrm{~mL}$ ) into EP tubes with heparin, centrifuged, and $0.1 \mathrm{~mL}$ of plasma was obtained and stored in a $-20^{\circ} \mathrm{C}$ refrigerator for measurement.

Tissue: SD rats in each group were anesthetized with $10 \%$ phenobarbital and sacrificed after 5 days of the experiment. The left kidney was extracted and placed in 
$4 \%$ tissue cell fixative for subsequent pathomorphological detection.

\section{Pathomorphological Observation}

The left kidney of SD rats in each group was fixed, dehydrated, transparent, waxed, embedded, and sectioned, and then stained with hematoxylin-eosin (HE). The effects of polymyxin B on the renal tissue structure were observed under a positive fluorescence microscope.

\section{Determination of SCr, BUN, and Urinary Protein Content}

Using a creatinine kit and a urea nitrogen kit, ${ }^{9,10}$ the serum creatinine ( $\mathrm{SCr}$ ) and blood urea nitrogen (BUN) levels in plasma were determined at $0,8,24,32,48,56,72,80$, and $96 \mathrm{~h}$. The urine of rats in each group was collected every day from the first to the fourth day of the experiment with a urinary protein quantitative test box for the determination of urinary protein content, and the daily urinary protein excretion volume was calculated according to the respective urinary volume of rats in each group. The results of each group were analyzed and compared. Oneway analysis of variance for repeated measures equipped with Dunnett's test (SPSS version 17.0 software; SPSS, Chicago, IL, USA) was employed to compare the levels among different groups. If the value of $P$ was below 0.05 , it was considered to be of statistical significance.

\section{Results}

\section{Experimental Physiology of Rats}

According to the current clinical dosage conversion of $2.5 \mathrm{mg} / \mathrm{kg}$ of polymyxin $\mathrm{B}$, a few minutes after the subcutaneous injection of $18 \mathrm{mg} / \mathrm{kg}$ of polymyxin $\mathrm{B}$, the rats all quickly displayed the phenomenon of different degrees of respiratory acceleration and heartbeat acceleration, and soon the whole body was paralyzed, the limbs were weak, and the palms and auricles appeared transiently dark purple, raising the suspicion of myasthenia and hypoxia. These adverse reactions increased gradually from a few minutes after administration to about half an hour after administration, and basically subsided after about $2 \mathrm{~h}$. A few rats were occasionally observed to have a transient scratching behavior after $8 \mathrm{~h}$ of administration. It was suspected that the drug caused an allergic reaction in the skin. In addition, the adverse reactions in Group B, such as respiratory acceleration, tachycardia, and limb weakness, were significantly reduced compared with Group A rats, receiving a dose of $18 \mathrm{mg} / \mathrm{kg}$. The rats in Groups $\mathrm{A}$ and $\mathrm{B}$ were successively exposed to declining mental state, body hair erection, limb and claw edema, urinary volume reduction, and precipitation of a white substance in the collected urine. At this point of the experiment, the drug was stopped. After 20 days of normal feeding, it was observed that most of the rats had local hair loss near the back of both sides of the hind limbs, and skin ulcers of different degrees and ranges which were suppurated. It was strongly suspected that the skin toxicity was secondary to the administration of polymyxin $\mathrm{B}$.

\section{Determination of SCr, BUN, and Daily Excretion of Urinary Protein}

$\mathrm{SCr}$, BUN, and urinary protein were measured in Groups A, B and C. Before administration, and after 8, $24,32,48,56,72,80$, and $96 \mathrm{~h}$ of continuous administration in the experiment, $\mathrm{SCr}$ in Group A was $56.98 \pm 12.42$ $\mu \mathrm{mol} / \mathrm{L}$, in Group B was $52.02 \pm 8.68 \mu \mathrm{mol} / \mathrm{L}$, and in Group $\mathrm{C}$ was $34.36 \pm 5.39 \mu \mathrm{mol} / \mathrm{L}$. The concentration of BUN was $9.86 \pm 4.58 \mathrm{mmol} / \mathrm{L}, 10.54 \pm 4.08 \mathrm{mmol} / \mathrm{L}$ and $3.55 \pm 0.73$ $\mathrm{mmol} / \mathrm{L}$ in Groups $\mathrm{A}, \mathrm{B}$, and $\mathrm{C}$, respectively. In the experiment, 24-hour urine of rats in each group was collected every day (days 1-4) after continuous administration, and the daily urinary protein excretion was measured and calculated. The daily urinary protein excretion was $5004.45 \pm 1333.84 \mu \mathrm{g}$ in Group A, 4808.04 $\pm 1444.42 \mu \mathrm{g}$ in Group B, and 2096.33 $\pm 215.28 \mu \mathrm{g}$ in Group C. The results showed that there were significant differences between Group A and Group C, and also between Group B and Group $\mathrm{C}(P<0.05)$. However, there was no significant difference between Group A and Group B $(P>0.05)$. Table 1 shows the results of the $\mathrm{SCr}, \mathrm{BUN}$, and daily urinary protein excretion in the three groups, and Figures 1, Figures 2, Figures 3 display more intuitive graphic comparisons of the data for each group.

Table I Determination of SCr, BUN, and Urinary Protein in Each Group ( $n=5$, Total Averages Over 96 h)

\begin{tabular}{|l|l|l|l|}
\hline & SCr $(\mu \mathrm{mol} / \mathbf{L})$ & BUN $(\mathbf{m m o l} / \mathbf{L})$ & Urinary Protein $(\boldsymbol{\mu g})$ \\
\hline Group A & $56.98 \pm 12.42^{*}$ & $9.86 \pm 4.58^{*}$ & $5004.45 \pm 1333.84^{*}$ \\
Group B & $52.02 \pm 8.68^{*}$ & $10.54 \pm 4.08^{*}$ & $4608.04 \pm 1444.42^{*}$ \\
Group C & $34.36 \pm 5.39$ & $3.55 \pm 0.73$ & $2096.33 \pm 215.28$ \\
\hline
\end{tabular}

Note: *Compared with Group C, $P<0.05$. 


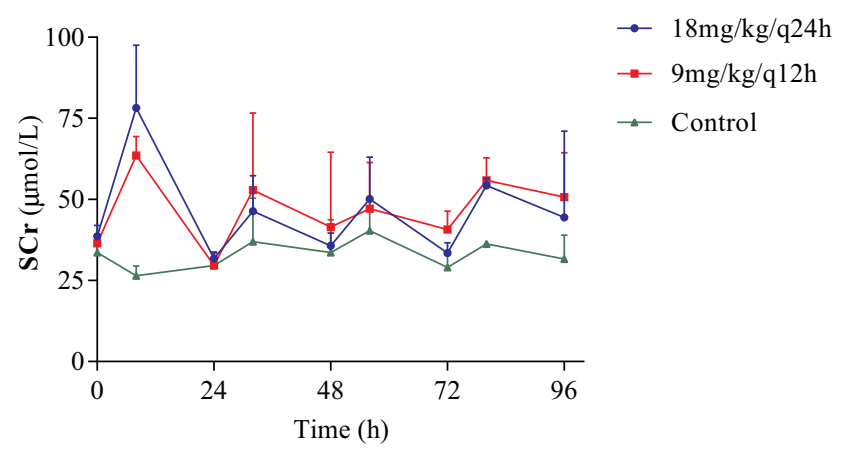

Figure I Comparison of serum creatinine $(\mathrm{SCr})$ of rats in each group.

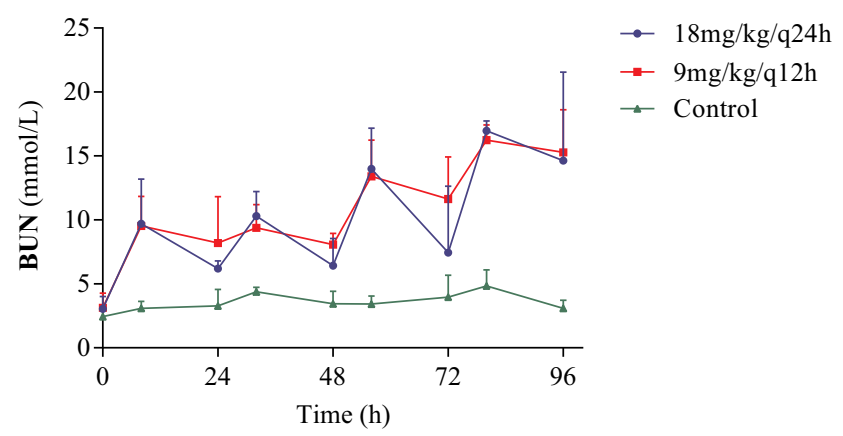

Figure 2 Comparison of blood urea nitrogen (BUN) content of rats in each group.

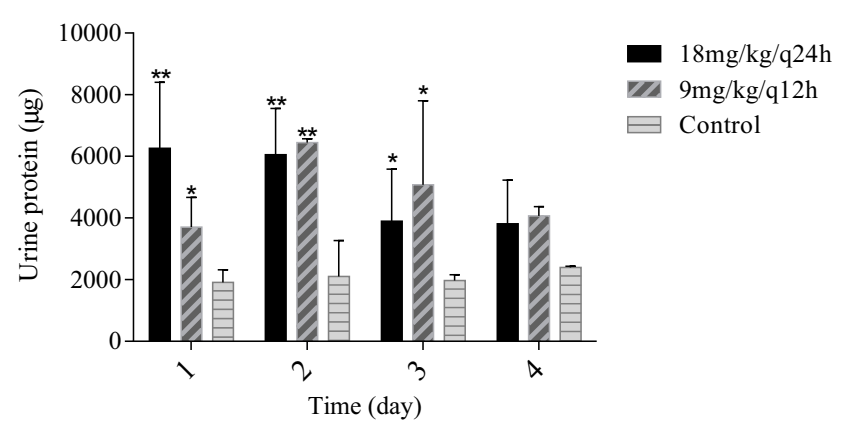

Figure 3 Comparison of daily urinary protein excretion between the drug groups and the control group $\left(* P<0.05,{ }^{*} P<<0.01\right)$.

\section{HE Staining}

The renal tissue sections of rats in each group were observed under a normal microscope. In the control group, the renal tissue morphology of rats was good, the epithelial cells of the renal tubules were not necrotic, and the glomerular structure was complete. However, the renal tissue morphology of rats in Group A was slightly changed, the interstitium was increased, a number of epithelial cells of the renal tubules were necrotic, and the glomerular structure was not damaged. In Group B, the renal tissue morphology of rats showed obvious changes, the interstitium had increased more, the number of renal tubules was sparse, the shape was irregular, most of them had differing degrees of epithelial cell necrosis, and the glomerular structure was slightly damaged. Figure 4 shows the left renal tissue sections of each group.

\section{Discussion}

The experimental results showed that polymyxin B is nephrotoxic to rats after subcutaneous injection. According to the dosage, the drug can cause different degrees of renal tubular epithelial cell necrosis, and even renal failure, owing to the destruction of the glomerular structure in severe cases. This is consistent with the literature reports on polymyxin B nephrotoxicity. ${ }^{9,11,12}$ The results showed that polymyxin B could also cause increases in $\mathrm{SCr}, \mathrm{BUN}$, and urinary protein. As the experiment is based on the clinical adult dose of polymyxin B, $2.5 \mathrm{mg} / \mathrm{kg} / \mathrm{q} 24 \mathrm{~h}$, converted to a dose of $18 \mathrm{mg} / \mathrm{kg} / \mathrm{q} 24 \mathrm{~h}$ for rats, the $\mathrm{SCr}$ and $\mathrm{BUN}$ levels of rats in each administration group are not particularly high; moreover, there is a significant fluctuation during the day, and the values of $\mathrm{SCr}$ and BUN often fluctuate in the range of high values and normal values during 5 days of continuous administration. According to the results of different frequencies of administration of experimental polymyxin $\mathrm{B}$ during a day, it was found that although there was no significant difference in the elevation of $\mathrm{SCr}$ and $\mathrm{BUN}$ between Group A and Group B, the fluctuation of $\mathrm{SCr}$ and BUN in Group B was more gentle than that in Group A. That is to say, compared with Group A, the conditions in Group B caused SCr and BUN to rise, but it was not easy for these levels to fall back. In addition, from the second day of the experiment, the level of urinary protein excretion in Group B was slightly higher than that in Group A. All of these results showed that compared with the $18 \mathrm{mg} / \mathrm{kg} / \mathrm{q} 24$ $\mathrm{h}$ dose, $9 \mathrm{mg} / \mathrm{kg} / \mathrm{q} 12 \mathrm{~h}$ administration had greater renal toxicity to rats. Referring to the relevant literature, Abdelraouf et $\mathrm{al}^{7}$ found through experiments in rats that at the same total daily dose of polymyxin $\mathrm{B}, 5 \mathrm{mg} / \mathrm{kg} / \mathrm{q} 6$ $\mathrm{h}$ produced greater nephrotoxicity than $20 \mathrm{mg} / \mathrm{kg} / \mathrm{q} 24$ h. Similarly, Liu et $\mathrm{al}^{10}$ proved through experiments, in which polymyxin B at $12 \mathrm{mg}$ of drug $/ \mathrm{kg}$ of body weight per day (once, twice, and thrice daily) was administered to rats over 3 days, that the most serious kidney injury occurred in the thrice-daily group. However, other researchers concluded that higher and less fractionated doses of polymyxins would cause more extensive renal damage. ${ }^{8,13}$ Nonetheless, the above results show that polymyxin B nephrotoxicity is related not only to the 

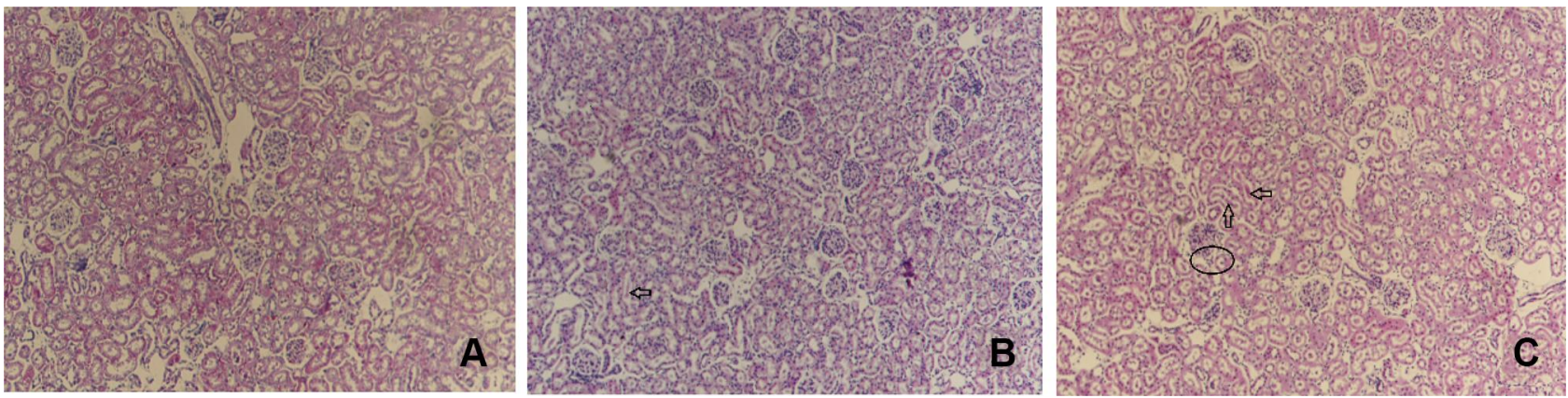

Figure $4 \mathrm{HE}$ staining results of rats in each group: (A) control group; (B) $18 \mathrm{mg} / \mathrm{kg} / \mathrm{q} 24 \mathrm{~h}$ group; (C) $9 \mathrm{mg} / \mathrm{kg} / \mathrm{q} / 2 \mathrm{~h}$ group. Arrows indicate the exfoliation and necrosis of renal tubular epithelial cells; the elliptical frame indicates glomerular injury.

size of the administered dose, but also to the frequency of administration. It can also be seen from the left renal tissue sections of rats in Figure 1 that the renal tissue damage in Group B is more serious than that of Group A, and the renal tissue of Group B not only shows morphological changes to the renal tubules and more tubular epithelial cell necrosis, but also has undergone destruction of the glomerular structure, which fully shows that the administration of polymyxin B twice a day causes more serious kidney injury than administration once a day, despite the total daily dose being the same.

In addition, we found that the $\mathrm{SCr}$ level in Group B was lower than that in Group A, and the urinary protein level in Group B was not as high as that in Group A on the first day, which suggested that the nephrotoxicity of polymyxin B rats was closely related to the dose, and the higher the dose, the greater the nephrotoxicity. ${ }^{9,14}$ The results showed that nephrotoxicity in rats injected with $9 \mathrm{mg} / \mathrm{kg} / \mathrm{q} 12 \mathrm{~h}$ for 5 days was higher than that in rats injected with $18 \mathrm{mg} / \mathrm{kg} / \mathrm{q} 24 \mathrm{~h}$ for 5 days. The reason for this result may be related to the non-passive transport of polymyxin B in renal tubular epithelial tissue. ${ }^{7}$ Abdelraouf et $\mathrm{al}^{4}$ concluded that polymyxin $\mathrm{B}$ was saturable into the proximal renal tubular epithelial cells of pigs, and was mainly absorbed through the cell apical membrane, suggesting that the megalin transporter plays an important role in the uptake and accumulation of polymyxin B in the kidney of rats. According to the relevant literature, ${ }^{6,15}$ polymyxin B-induced nephrotoxicity is related to DNA damage of related cells caused by the drug, resulting in chromosome segregation and genomic instability in cellular mitosis, as well as oxidative stress, mitochondrial damage, and changes in the lactate dehydrogenase activity of target cells, resulting in apoptosis and necrosis of renal proximal tubular epithelial cells. ${ }^{16,17}$
Relevant experimental studies ${ }^{5,18}$ have shown that, after intravenous injection of polymyxin B for several hours, the distribution of polymyxin B in blood, heart, liver, spleen, lung, kidney, muscle, brain, and other tissues of rats has the highest concentration in renal tissue, which may be the objective cause of renal tubular epithelial cell damage and nephrotoxicity in rats. However, why does a once-daily dose of polymyxin $\mathrm{B}$ in rats produce a more serious hypoxic condition in systemic tissues than a twice-daily dose? Why does a daily dose divided into two administrations produce more severe nephrotoxicity than a daily dose administered once? Why does polymyxin B tend to accumulate in the kidney after subcutaneous injection and absorption? Our research has limitations, including that the number of samples in each experimental group is small, and the drug dosing scheme design could be further optimized. It is difficult to distinguish the tissue hypoxic-ischemic damage caused by the drug from the direct kidney damage caused by the drug. These related issues are worthy of further research.

\section{Summary}

The effect of polymyxin B on renal toxicity in rats was studied. In the experimental study on the renal toxicity of polymyxin B to rats, through the detection of several physiological indices such as $\mathrm{SCr}, \mathrm{BUN}$, and urinary protein, and the observation of pathological sections of renal tissue, it was found that polymyxin B could increase the content of $\mathrm{SCr}, \mathrm{BUN}$, and urinary protein in rats to varying degrees, and the daily dose given in two consecutive administrations had a greater effect than the daily dose $\mathrm{n}$ one continuous administration on the physiological indices of $\mathrm{SCr}$ and $\mathrm{BUN}$ in rats. The standard effect is more obvious. According to the pathological sections of renal tissue, the damage to rats' renal tissue is more serious after twice-daily administration of polymyxin 
B than after once-daily administration, and the nephrotoxicity is more serious after twice-daily administration of polymyxin B. The results of this study can provide some reference and help for further study of the clinical safety and rational use and nephrotoxicity of polymyxin B.

\section{Acknowledgment}

This study was supported by a grant from Zhejiang Provincial Medical Association (grant no. 2020ZYC-A116).

\section{Disclosure}

The authors report no conflicts of interest for this work.

\section{References}

1. Solomon SL, Oliver KB. Antibiotic resistance threats in the United States: stepping back from the brink. Am Fam Physician. 2014;89 (12):938-941.

2. Avedissian SN, Liu J, Rhodes NJ, et al. A review of the clinical pharmacokinetics of polymyxin B. Antibiotics (Basel). 2019;8(1). doi:10.3390/antibiotics8010031.

3. Tsuji BT, Pogue JM, Zavascki AP, et al. International consensus guidelines for the optimal use of the polymyxins: endorsed by the American College of Clinical Pharmacy (ACCP), European Society of Clinical Microbiology and Infectious Diseases (ESCMID), Infectious Diseases Society of America (IDSA), International Society for Anti-infective Pharmacology (ISAP), Society of Critical Care Medicine (SCCM), and Society of Infectious Diseases Pharmacists (SIDP). Pharmacotherapy. 2019;39(1):10-39. doi:10.1002/phar.2209

4. Abdelraouf K, Chang KT, Yin TJ, Hu M, Tam VH. Uptake of polymyxin B into renal cells. Antimicrob Agents Chemother. 2014;58 (7):4200-4202. doi:10.1128/AAC.02557-14

5. Manchandani P, Zhou J, Ledesma KR, et al. Characterization of polymyxin B biodistribution and disposition in an animal model. Antimicrob Agents Chemother. 2016;60(2):1029-1034. doi:10.1128/AAC.02445-15

6. Vattimo Mde F, Watanabe M, da Fonseca CD, Neiva LB, Pessoa EA, Borges FT. Polymyxin B nephrotoxicity: from organ to cell damage. PLoS One. 2016;11(8):e0161057. doi:10.1371/journal.pone.0161057

7. Abdelraouf K, Braggs KH, Yin T, Truong LD, Hu M, Tam VH. Characterization of polymyxin B-induced nephrotoxicity: implications for dosing regimen design. Antimicrob Agents Chemother. 2012;56 (9):4625-4629. doi:10.1128/AAC.00280-12
8. Okoduwa A, Ahmed N, Guo Y, et al. Nephrotoxicity associated with intravenous polymyxin B once- versus twice-daily dosing regimen. Antimicrob Agents Chemother. 2018;62(8). doi:10.1128/ AAC.00025-18.

9. Manchandani P, Zhou J, Babic JT, Ledesma KR, Truong LD, Tam VH. Role of renal drug exposure in polymyxin B-induced nephrotoxicity. Antimicrob Agents Chemother. 2017;61(4). doi:10.11 28/AAC.02391-16

10. Liu J, Pais GM, Avedissian SN, et al. Evaluation of dose-fractionated polymyxin B on acute kidney injury using a translational in vivo rat model. Antimicrob Agents Chemother. 2020;64(5). doi:10.1128/ AAC.02300-19.

11. Aggarwal R, Dewan A. Comparison of nephrotoxicity of Colistin with Polymyxin B administered in currently recommended doses: a prospective study. Ann Clin Microbiol Antimicrob. 2018;17(1):15. doi:10.1186/s12941-018-0262-0

12. Soares DS, Reis ADF, Silva Junior GBD, et al. Polymyxin-B and vancomycin-associated acute kidney injury in critically ill patients. Pathog Glob Health. 2017;111(3):137-142. doi:10.1080/20477724. 2017.1309338

13. Wallace SJ, Li J, Nation RL, et al. Subacute toxicity of colistin methanesulfonate in rats: comparison of various intravenous dosage regimens. Antimicrob Agents Chemother. 2008;52(3):1159-1161. doi:10.1128/AAC.01101-07

14. Nelson BC, Eiras DP, Gomez-Simmonds A, et al. Clinical outcomes associated with polymyxin $\mathrm{B}$ dose in patients with bloodstream infections due to carbapenem-resistant Gram-negative rods. Antimicrob Agents Chemother. 2015;59(11):7000-7006. doi:10.112 8/AAC.00844-15

15. Yun B, Zhang T, Azad MAK, et al. Polymyxin B causes DNA damage in HK-2 cells and mice. Arch Toxicol. 2018;92 (7):2259-2271. doi:10.1007/s00204-018-2192-1

16. Azad MA, Akter J, Rogers KL, Nation RL, Velkov T, Li J. Major pathways of polymyxin-induced apoptosis in rat kidney proximal tubular cells. Antimicrob Agents Chemother. 2015;59(4):2136-2143. doi:10.1128/AAC.04869-14

17. Weber EJ, Lidberg KA, Wang L, et al. Human kidney on a chip assessment of polymyxin antibiotic nephrotoxicity. JCI Insight. 2018;3(24). doi:10.1172/jci.insight.123673.

18. Abdelraouf K, He J, Ledesma KR, Hu M, Tam VH. Pharmacokinetics and renal disposition of polymyxin B in an animal model. Antimicrob Agents Chemother. 2012;56(11):5724-5727. doi:10.1128/AAC.01333-12

\section{Publish your work in this journal}

Drug Design, Development and Therapy is an international, peerreviewed open-access journal that spans the spectrum of drug design and development through to clinical applications. Clinical outcomes, patient safety, and programs for the development and effective, safe, and sustained use of medicines are a feature of the journal, which has also been accepted for indexing on PubMed Central. The manuscript management system is completely online and includes a very quick and fair peer-review system, which is all easy to use. Visit http://www. dovepress.com/testimonials.php to read real quotes from published authors. 